\title{
POLA PENDIDIKAN BANGSA ISRAEL SEBAGAI MODEL DALAM PENANAMAN IMAN KEPADA GENERASI BARU
}

\author{
Oleh: Darmanto ${ }^{1}$
}

\begin{abstract}
Education occupies an important position in the sustainability of a nation, so keep awake and not lose generation, (lose generation = a generation that does not believe in God). Israelites or Jews have a Pattern of education inherited from generation to generation to maintain the purity of their faith.Religion and dailly activities are not separated, Jews are believers and

believe in one God; To keep it's parents teaching their childrens at home and in the community education by Jewish teachers (rabbi) in the synagogue.God instructs parents to teach their childrens and grandchildrens of the God in any time, any where; To keep the purity of a generation who fear God.
\end{abstract}

Keywords: education, generation, family, community.

\section{Pendahuluan}

Bangsa Israel adalah bangsa atau umat pilihan Allah, yang secara pemerintahan bangsa langsung dipimpin oleh Allah; dalam sistem pemerintahan disebut pemerintahan "teokrasi," dimana pucuk kepemimpinan adalah di tangan Tuhan semesta alam (ALLAH). Dan dalam perjalanan waktu saat bangsa Israel menjadi sebuah bangsa yang besar tradisitradisi kehidupan dipimpin TUHAN menjadi bagian yang harus dituturkan kepada anak-cucu secara terus menerus agar tidak kehilangan jejak, apalagi saat akhirnya Israel memilih untuk dipimpin oleh "raja" dan tidak lagi memakai pemerintahan teokrasi.

Akhirnya kita menemukan fakta ada pendidikan bagi orang-orang Israel di "sinagoge," yang secara sejarah sangat susah menemukan kapan mulai ada pendidikan di sinagoge-sinagoge; tetapi faktanya kita menemukan dalam Perjanjian Baru bahwa Yesus juga para rasul sering datang dan mengajar di sinagoge. Biasanya pada hari sabat orang Yahudi akan berkumpul di sinagoge untuk mendengar guru Yahudi (rabi) membaca Kitab Suci dan Taurat. Juga dalam hari-hari lain anak-anak lelaki Yahudi di ajar di sinagogesinagoge untuk memperdalam pendidikan agama, selain di rumah setiap anak-anak mendapat pengajaran dari orang tua mereka. Daud adalah salah satu contoh hasil pendidikan Yahudi dengan pendidikan agama yang baik, tetapi juga pelajaran tata krama, musik juga latihan keprajuritan (1 Samuel 16:18).

${ }^{1}$ Darmanto adalah Dosen STT Nazarene Indonesia, dan saat ini sebagai Ketua Program Studi Teologi; menyelesaikan program S1 dan S2 Teologi Kependetaan di STT Nazarene Indonesia, dan sekarang ini terlibat dalam Pelayanan Pengembangan Anak dan Pelayanan Lintas Budaya. 


\section{Keluarga Yahudi}

Dalam tradisi Yahudi pendidikan agama merupakan tanggung jawab orang tua, tanpa terkecuali apakah orang tua mereka terlalu sibuk dengan pekerjaannya. Orang tua harus mengajar anak-anak mereka; bahkan orang tua mengajar sampai kepada cucu mereka, karena memang kebanyakan keluarga Yahudi tinggal dalam satu rumah dalam keluarga besar.

Nenek moyang kaum Israel, Abraham, Ishak dan Yakub menjadi guru bagi seluruh keluarganya. Sebagai bapak-bapak dari bangsanya, mereka bukan saja menjadi imam yang merupakan pengantara antara Tuhan dengan umat-Nya, tetapi juga menjadi guru yang mengajarkan tentang perbuatan-perbuatan Tuhan yang mulia itu dengan segala janji Tuhan yang embawa berkat kepada Israel turun-temurun. Tuhan telah memilih dan memanggil Abraham dari jauh untuk melayani kehendak-Nya yang agung itu guna keselamatan seluruh umat manusia. Bimbingan dan maksud Tuhan itu perlu dijelaskan kepada segala anak cucunya. ${ }^{2}$

Ulangan 4:9; 11:19; 32:46, memberitahukan kepada kita bagaimana Allah memerintahkan kepada setiap orangtua Yahudi untuk mengajar tentang Allah kepada anakanak dan cucu mereka.

Tetapi waspadalah dan berhati-hatilah, supaya jangan engkau melupakan hal-hal yang dilihat oleh matamu sendiri itu, dan supaya jangan semuanya itu hilang dari ingatanmu seumur hidupmu. Beritahukanlah kepada anak-anakmu dan kepada cucu cicitmu semuanya itu...(Ulangan $4: 9$ )

Kamu harus mengajarkannya kepada anak-anakmu dengan membicarakannya, apabila engkau duduk di rumahmu dan apabila engkau sedang dalam perjalanan, apabila engkau berbaring dan apabila engkau bangun (Ulangan 11:19)

Setelah Musa selesaimenyampaikan segala perkataan itu kepada seluruh orang Israel, berkatalah ia kepada mereka: "Perhatikanlah segala perkataan yang keperingakan kepadamu pada hari ini, supaya kamu memerintahkannya kepada anak-anakmu untuk melakukan dengan setia segala perkataan hukum Taurat ini, (Ulangan 32:46)

Orangtua di dalam rumah tangga Yahudi sangat berperan dalam mendidik anakanaknya, orangtua mengajar langsung tentang kebiasaan, tatakrama dan kepercayaan kepada Allah; orangtua membawa anak-anak mereka ke Bait Allah. Kita bisa melihat bagaimana Yusuf dan Maria membawa Yesus pada waktu berumur 12 tahun ke Bait Allah (Lukas 2:41)

Asaf sang pemazmur dalam Mazmur 78 menuliskan bait-bait nyanyian tentang pentingnya memberitahukan atau mengajar kepada anak-anak agar takut akan Tuhan, memegang perintah Allah dan tidak seperti kegagalan nenek moyang mereka yang jatuh bangun bahkan gagal mengikuti kehendak Allah.

\footnotetext{
${ }^{2}$ Dr.E,G. Homrighousen dan Dr.I.H.Enklaar. Pendidikan Agama Kristen (Jakarta: BPK Gunung Mulia, 2007), 2.
} 


\section{Pelajaran Dari Sejarah(Mazmur 78:1-7)}

Pasanglah telinga untuk pengajaranku, hai bangsaku, sedengkanlah telingamu kepada ucapan mulutku. Aku akan membuka mulut mengatakan amsal,aku mau mengucapkan teka-teki dari zaman purbakala. Yang telah kami dengar dami ketahui, dan yang diceritakankepada kami oleh nenek moyang kami.kami tidak hendak menyembunyikan kepada anak-anak mereka, tetapi kami akan menceritakan kepadaangkatan yang kemudian puji-pujian kepada TUHAN dan kekuatan-Nya dan perbuatan-perbuatan ajaib yang telah dilakukan-Nya.Telah ditetapkan-Nya peringatan di Yakub dan hukum Taurat diberi-Nya di Israel, nenek moyang kita diperintahkanNya untuk memperkenalkannya kepada anak-anak mereka, supaya dikenal oleh angkatan yang kemudian, supaya anak-anak, yang akan lahir kelak, bangun dan menceritakannya kepada anak-anak mereka,supaya mereka menaruh kepercayaan kepada Allah dan tidak melupakanperbuatan-perbuatan Allah, tetapi memegangperintah-perintah-Nya.

Jadi sangat jelas bahwa bagaimana warna tingkah laku dan iman anak-anak dan generasi berikutnya merupakan gambaran seperti orang tua sesungguhnya mendidik mereka; itu sebabnya Allah menaruh kepedulian kepada anak-anak, karena mereka generasi yang akan meneruskan sejarah kehidupan iman nenek moyang mereka.

Anak-anak mutlak menempati posisi khusus dalam gereja. Mereka adalah benih gereja, harapan masa depan. Tuhan sendiri memberi tempat khusus bagi mereka. Ia mendatangkan kerajaan-Nya turun temurun, dari orang tua kepada anak-anak. "Lahir dalam rumah Kristen" bukanlah kebetulan, melainkan karunia dan pimpinan Tuhan yang tak dapat di sangkal. Baptisan adalah tanda dan materai yang indah dari kenyataan tersebut. Tapi baptisan itu juga mewajibkan orangtua dan gereja menjaga kualitas pendidikan ajaran Kristen, baik di rumah tangga, di sekolah maupun dalam katekisasi $^{3}$

Berkaca dengan sejarah Israel bagaimana pentingnya keluarga (oikos) yang terdiri dari Ayah, Ibu, Anak-anak dan setiap orang yang ada dalam satu rumah/kemah, menjadi bagian dalam mewariskan ajaran Iman dan segala pembelajaran hidup, maka pendidikan di dalam keluarga tidak bisa dikesampingkan, walaupun sesibuk apapun orang tua dalam pekerjaan. Karena kalau tidak mendidik anak-anak sejak dini dalam keluarga, maka suatu generasi bisa menjadi generasi yang "terhilang," dalam artian generasi yang tidak takut TUHAN dan bahkan tidak mengenal TUHAN.

Sering orangtua menyerahkan pendidikan anak-anak termasuk pendidikan agama (iman) kepada sekolah dan gereja; orangtua merasa sudah memberikan yang dibutuhkan untuk kebaikan masa depan anak. Itu sesungguhnya hanya sebagian dari keutuhan pendidikan bagi anak; karena anak-anak Kristen (orang percaya) membangun pendidikan bagi anak secara bersama, yaitu: Keluarga, Sekolah dan Gereja.

${ }^{3}$ G Reimer. Ajarlah Mereka. Pedoman Ilmu Katekese(Jakarta: Yayasan Komunikasi Bina Kasih/OMF, 1999), 12 


\section{Sekolah Orang Yahudi}

Di Israel Purba, perbuatan-perbuatan Allah (Yahwe) yang tercatat dalam kitab Taurat ditanamkan oleh para rabi ke dalam hati sanubari murid-muridnya. Segala pengajaran dilakukan secara lisan dari generasi ke generasi, baik melalui orang tua maupun oleh para guru (rabi).

\section{Beth-ha-sefer}

Pada abat-abad pertama masehi, bangsa Yahudi mengadakan semacam sekolah dasar yang disebut "beth-ha-sefer"(beth=rumah, sefer=kitab); yang artinya "rumah sang kitab". Di sekolah inilah pengetahuan tentang Taurat diajarkan kepada anak-anak Yahudi. Taurat dibaca berulang-ulang dan anak-anak wajib menghafalkan secara seksama dan harafiah. Sejak umur 6 atau 7 tahun anak-anak yahudi sudah di bawa oleh orang tuanya ke pengajaran rabi di sekolah ini; dengan tujuan untuk mendapat pengetahuan tentang Taurat. Dalam kehidupan agama Islam kebiasaan ini masih terus dilestarikan, yaitu anak-anak sejak dini belajar membaca dan menghafal Kitab Suci, tanpa harus mengerti arti dan maksud dari bacaan dan hafalan tersebut.

\section{Beth-ha-midrash}

Tingkat yang lebih tinggi untuk pengajaran hukum di beth-ha-sefer diberikan di "beth-ha-midrashy" (beth=rumah, midrash=pengajaran) yang memiliki arti "rumah pengajaran." Di sekolah ini bukan hanya siswa dituntut untuk menghafal Taurat secara literal, melainkan sudah diajarkan tentang manfaat dan makna Taurat itu. Pada usia 12-13 tahun anak-anak yahudi dituntut sudah bisa sepenuhnya menaati dan melaksanakan hukum Yahudi, yaitu "mitswoth," dan pada tahap ini anak lelaki Yahudi telah dianggap sebagai "barmitswa," yang artinya "anak-anak hukum taurat."

\section{Kurikulum dan Bahan Pengajaran}

Berbicara tentang pendidikan atau pengajaran, tentu juga harus mengerti tentang bahan dan kurikulum yang dipakai dalam belajar; termasuk juga dalam pengajaran Yahudi. Pengajaran anak-anak yahudi mulai dari usia dini yang mendapat pendidikan langsung oleh orang tua mereka di rumah, tentang tatakrama, dan iman kepada Allah, beserta ritual keagamaan Israel.

Umur 5 tahun; anak-anak mulai diberi pelajaran dasar membaca Taurat. Pada umur ini anak-anak mulai membaca dan menulis, terutama membaca dan menghafalkan Taurat. 
Umur 10 tahun; mulai dengan mitswa (pengajaran); pada tataran ini anak-anak sudah diajar tentang makna dan arti dari hukum Taurat, bukan lagi hanya menghafal, tetapi sudah tahu maknanya.

Umur 12-13 tahun; menjalani sebagai bar-mitswa, (menjalankan peraturan/hukum Yahudi. Mereka sudah dianggap mumpuni dalam hal hukum taurat dan melaksanakannya, sehingga anak-anak di taraf ini disebut juga anak syariat atau anak Torah (The son of law).

Ada bukti bahwa pelajaran menghafal Taurat ini merupakan dasar keimanan anak-anak Yahudi yang akhirnya anak-anak Yahudi sangat tahu identitasnya, keyakinannya dan sangat militan dengan imannya kepada Allah (Yahwe). Bagaimana dengan orang percaya saat ini? Apakah orang tua dan guru-guru agama baik di sekolah umum maupun di gereja mengajar anak-anak akan pentingnya menghafal firman Tuhan?

Pendidikan Taurat Yahudi bisa terlaksana dengan baik karena adanya komunitas (jemaat) yang beriman teguh. Pendidikan itu dilaksanakan di sinagoge, sebagai tempat berkumpul, belajar agama dan beribadah, karena mereka mau mengajar kepada anak-anak agar kelak menjadi dewasa dalam segala aspek kehidupan dan menjadi bagian dari umat di sinaoge. Ini sangat penting bagi kita untuk membawa anak-anak ke rumah Tuhan (gereja sekarang) agar anak-anak tumbuh dewasa dalam segala aspek kehidupan termasuk imannya sehingga akan menjadi bagian dan meneruskan komunitas orang percaya dalam gereja. Sesungguhnya antara orangtua di rumah, guru di sekolah umum dan guru sekolah minggu di gereja, bias duduk bersama dalam komunitas pengajaran yang saling bergandengtangan dalam keberhasilan pengajaran kepada anak-anak, sebagai generasi penerus.Ada empat pelajaran utama di Sinagoge, yaitu:

\section{Syema Yisrael}

Syema Yisrael artinya: "Dengarlah hai orang Israel," yang merupakan kredo atau pengakuan iman dan pengucapan syukur yang dibaca tiap hari pada waktu pagi dan malam dalam ibadah di sinagoge.

Dengarlah, hai orang Israel: TUHAN itu Allah kita, TUHAN itu esa. Kasihilah TUHAN, Allahmu, dengan segenap hatimu dan dengan segenap kekuatanmu. Apa yang kuperintahkan kepadamu pada hari ini haruslah engkau perhatikan, haruslah engkau mengajarkannya berulang-ulang kepada nak-anakmu dan membicarakannya apabila engkau duduk di rumahmu, apabila engkau sedang dalam perjalanan, apabila engkau berbaring dan apabila engkau bangun. Haruslah juga engkau mengikatkannya sebagai tanda pada tanganmu dan haruslah menjadi lambang di dahimu, dan haruslah engkau menuliskannya pada tiang pintu rumahmu dan pada pintu gerbangmu. (Ulangan 6:4-9)

Dengarlah, hai orang Israel; adalah bagian yang sebut sebagai Syema/Shema (ibrani: Shama=mendengar). Bagian ini sangat di kenal oleh orang Yahudi pada zaman Yesus karena diucapkan setiap hari oleh orang Yahudi yang saleh dan secara tetap di ibadah sinagoge. Shema ini merupakan pernyataan terbaik tentang kodrat monotheisme Allah; pernyataan ini diikuti dengan perintah ganda kepada bangsa Israel; Untuk mengasihi Allah dengan segenap hati, jiwa dan kekuatan, dan untuk mengajarkan iman mereka dengan tekun kepada anak-anak mereka. ${ }^{4}$

\footnotetext{
${ }^{4}$ Alkitab Penuntun Hidup Berkelimpahan (Jakarta: Lembaga Alkitab Indonesia, 2005), 285.
} 


\section{Syemone Esre}

Syemone Esre adalah doa yang terdiri dari 18 pengucapan, yang diucapkan setiap hari; pagi, sore dan malam dalam ibadah di sinagoge. Doa ini mengndung ucapan syukur dan puji-pujian terhadap Allah Abraham, Ishak dan Yakub, serta doa akan pemulihan Yerusalem dan Tahta Daud. Sampai sekarang ini menjadi bagian penting dalam doa bagi orang Yahudi.

\section{Tehillah}

Tehillah adalah pembacaan Taurat dengan di lagukan/dilantunkan; seperti orang moslem membaca Al'Quran (tahlil). Pembcaan Taurat menduduki psoisi penting, karena Taurat adalah bagian Kitab Suci yang sentral bagi orang Yahudi. Iman dan kehidupan orang Yahudi seluruhnya didasarkan atas Taurat. Pengajaran dengan cara dibacakan dan dijelaskan dalam ibadah di sinagoge, dan ini merupakan tradisi paling tua dalam kehidupan orang Yahudi.

\section{Hari-hari Raya}

Anak-anak Yahudi diajar untuk memelihara hari raya dan peringatan hari besar yang lain; ada beberapa hari raya penting yang selalu menjadi bagian perayaan kehidupan orang Yahudi, yaitu:Sabath (Keluaran 23; Ulangan 5:2)Hari Raya Tujuh Minggu (Kel.34:22; Ul.16:10) ; Hari raya Roti Tak Beragi (Kel.23:15; 34:18; Mat.26:17) ; Hari Raya Pondok Daun (Im.23:34; Ul.16:13; Yoh.7:2) ; Hari raya Pentakosta (KPR.2:1; 20:16; 1 Kor.16:8) ; Hari Raya Pentabisan bait Allah/ Hanukah (Yoh.10:22) ; Hari Raya Pengumpulan Hasil (Kel.23:16; 34:22) ; Hari raya Pendamaian/Yon Kippur (Im.23:26; 35:9) ; Hari Raya Purim (Kitab Ester) ; Hari raya Paskah (Kel.12:11; Im.23:5; Mat.26:2)

\section{Tempat dan Sistem Pembelajaran}

Dalam tradisi Israel kuno, kita bisa melihat bagaimana orang-orang Israel diperintahkan dan dibagi-bagi oleh Daud (I Tawarikh 25) di bawah ayah mereka anak-anak Israel didik dan dilatih melaksanakan tugas pelayanan di Bait Allah. Ada indikasi bahwa anak-anak Israel didik oleh ayahnya di rumah mereka masing-masing.

Di Israel segala sesuatu harus saling membantu dan bekerjasama untuk mendidik anak-anak dan orang dewasa agar menjadi anggota-anggota persekutuan agama itu, yang insaf akan panggilannya dan dengan segenap hatinya ingin mengabdi kepada Tuhan dalam segala gerak-gerik hidup mereka. Untuk itu juga dipergunakan masamasa raya yang memperingakan kaum Israel akan peristiwa-peristiwa yang besar yang dialami nenk moyang mereka zaman dulu, misalnya perayaan pesta Paskah. Berhubung dengan hari-hari raya itu bapa-bapa menceritakan kepada anak-anaknya 
tentang segala pimpinan dan berkat Tuhan pada masa lampau, supaya menjadi pelajaran dan penghiburan bagi merka sekalian pada masa kini..$^{5}$

Pengajaran atau bimbingan dalam rumah pengajaran (beth-ha-midrasy) erat kaitanya dengan rumah ibadat (sinagoge) orang yahudi. Di sisni anak-anak duduk di kaki guru-guru Torah dan menerima pengajaran. Dalam kenyataannya tidak semua anak-anak Yahudi mendapat kesempatan atau bisa mengikuti jenjang beth-ha-midrash; kebanyakan dari anakanak Yahudi hanya dapat mengikuti pengajaran dalam pembacaan Torah di rumah ibadah (sinagoge) seminggu sekali pada hari Sabath.

Kita tidak bisa mengetahui dengan tepat kapan pertama kalinya sekolah-sekolah sinagoge didirikan; ada pendapat itu sejak pada masa pembuangan di Babel, saat orang Israel/Yahudi tidak bisa datang ke Bait Allah, mereka berkumpul dan berdoa di sinagoge. Kapanpun sekolah ini dimulai, akhirnya sampai sekarang menjadi bagian penting dari pendidikan orang Yahudi. Terlebih sinagoge itu menjadi ikon Yudaisme.

Selama masa pembuangan ke Babel, kaum Yahudi itu makin lama makin sadar lagi akan amanat dan panggilannya. Para katib mereka banyak mencurahkan perhatian kepada kitab-kitab suci bangsanya. Dibangunlah rumah-rumah sembahyang dan sekolah-sekolah agama, tempat diajarkannya kepada jemaat Yahudi itu segala tradisi agama yang telah diserahkan nenek moyangnya berabad-abad lamanya. Dan sekembalinya kaum yahudi itu ke tanah airnya, maka pembacaan taurat mulai memegang peranan yang amat penting di pusat hidup keagamaan mereka. Ilmu ketuhanan bertambah-tambah diutamakan; banyak sarjana yahudi yang menyelidiki dan menafsirkan kitab-kitab suci dengan teliti. Sekolah-sekolah dan mazhab rabbi yang masyur itu mulai muncul, berkembang dan berkuasa. ${ }^{6}$

Dalam ruang kelas itu terdapat sebuah podium kecil yang tinggi letaknya tempat guru (rabi) duduk bersilang kaki. Di depan guru terdapat sebuah rak pendek dengan gulungangulungan naskah yang berisi bagian-bagian pilihan dari Perjanjian Lama. Buku-buku pelajaran tidak ada; murid-murid duduk di lantai dekat kaki guru tersebut. Kelas-kelas tidak digolongkan menurut usia; semua murid belajar bersama-sama dalam ruangan yang sama. Dalam praktek di kelas, guru akan menyalin sebuah ayat untuk dibaca keras-keras oleh para siswa yang lebih kecil sampai mereka menguasai ayat tersebut; sementara itu guru membantu anak-anak yang lebih tua untuk membaca satu perikop dari Kitab Imamat. Bagi kita mungkin situasi kelas dan kebisingannya akan mengganggu, tetapi tidak untuk mereka.Butuh konsentrasi tinggi dan focus yang jelas akan tugas pembelajaran masing-masing anak untuk bisa menyerap pembelajaran dalam suasana hiruk pikuk kebersamaan ini; malah saya membayangkan mungkin ini akan menjadi kebersamaan yang saling menolong, misalnya ada yang membaca dan melantunkan Taurat tidak tepat, maka yang lain atau murid yang lebih besar akan menolong membetulkan; dan kebersamaan komunitas ini justru semakin memperkuat rasa kebersamaan dan loyalitas sebagai satu bangsa, satu agama dan kepercayaan.

\footnotetext{
${ }^{5}$ Dr.E,G. Homrighousen dan Dr.I.H.Enklaar. Pendidikan Agama Kristen (Jakarta: BPK Gunung Mulia, 2007), 4.

${ }^{6}$ Dr.E,G. Homrighousen dan Dr.I.H.Enklaar. Pendidikan Agama Kristen (Jakarta: BPK Gunung Mulia, 2007), 5.
} 


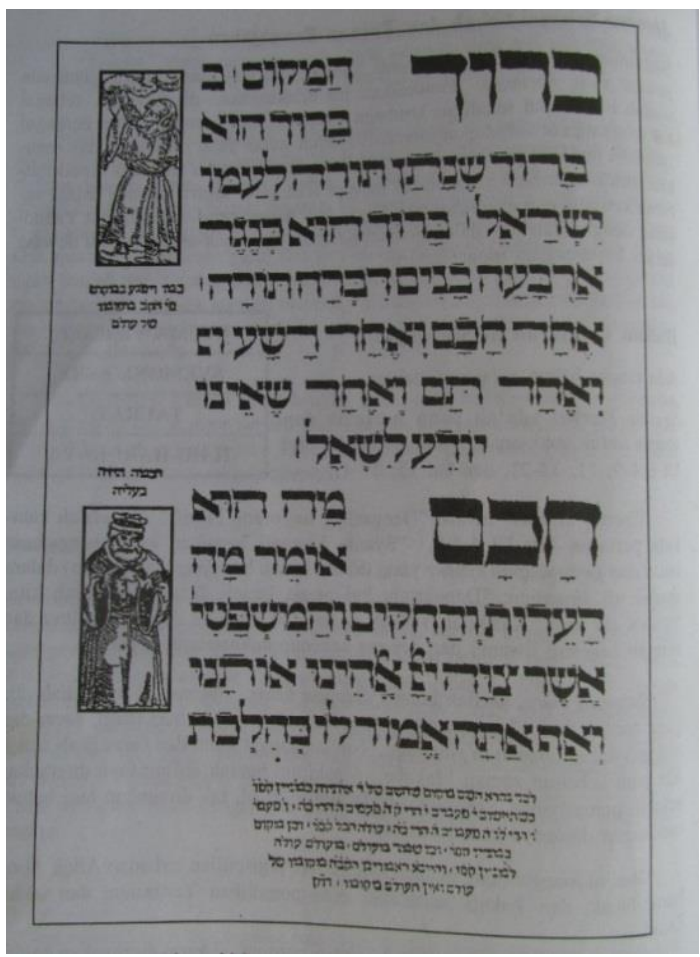

\author{
Gambar 1: \\ Halaman Muka "Magada," ajaran Yahudi (tahun \\ $1526)^{7}$
}

\title{
Kesimpulan
}

Kita bisa melihat benang merah yang tak terputus dalam model pembelajaran tentang keimanan kaum Yahudi atau orang Israel, yaitu bahwa anakanak ada di bawah tanggung jawab orang tua untuk memperkenalkan Allah yang Esa dalam hidup mereka dalam keseharian, dari zaman Israel kuno sampai Israel/yahudi masa sekarang; juga secara komunitas (bangsa) bagaimana mereka menjaga generasi penerus dengan tetap mengajarkan tentang Allah dan tradisi yang harus diikuti.

Tuhan menggunakan orangtua yang takut akan Tuhan (saleh) untuk memimpin keluarga yaitu anak-anak dan seluruh kaum yang ada dalam keluarganya, untuk hidup benar di dalam Tuhan; sehingga akan mucul generasi yang takut akan Tuhan. Dengan kata lain kita bisa belajar tentang kualitas iman anak-anak dan kaitannya dengan kesalehan orangtua; ada banyak contoh di dalam alkitab yang bisa kita pelajari berkaitan pengaruh Orangtua dalam menjaga iman kepercayaan anak-anak kepada Allah.

Dalam kesimpulan tulisan ini, ijinkanlah penulis menceritakan ulang tentang keluarga-keluarga saleh yang sangat mempengaruhi generasi berikutnya, yang ada dalam Alkitab.

\section{Orangtua Samuel}

Sauel adalah anak dari Elkana dan Hana. Elkana adalah orang yang saleh dan taat pada Tuhan, bukti kesalehan Elkana bisa kita lihat dari ketekunannya pergi ke syilo untuk beribadah; dimana ia juga membawa seluruh keluarganya untuk beribadah. Elkana menunjukkan bahwa ia adalah seorang imam yang baik untuk keluarganya. Sedangkan istrinya Hana adalah seorang pendoa; Ia berdoa memohon kepada Tuhan agar diberi anak, Ia juga dengan tulus dan berani mengembalikan anak pemberian Tuhan itu kepada Tuhan; ini menunjukkan bahwa Hana sangat dekat dan percaya ddengan Tuhan.

Kesalehan Elkana dan hana mendatangkan berkat yang luar biasa yaitu lahirnya Samuel; dan akhirnya Samuel menjadi hamba Tuhan yang luar biasa bagi umat Israel, 1999),38.

${ }^{7}$ G Reimer. Ajarlah Mereka. Pedoman Ilmu Katekese(Jakarta: Yayasan Komunikasi Bina Kasih/OMF, 
seorang nabi besar penyambung lidah Allah yang muncul setelah ratusan tahun masa kekosongan firman Tuhan.

\section{Orangtua Simson}

Simson adalah anak dari Manoakh, ibunya bahkan tidak disebutkan dalam Alkitab. Sebelum Simson dilahirkan, Ia telah ditetapkan menjadi Nazir Allah seumur hidupnya. Manoakh tahu dan sadar akan kehendak Tuhan itu, maka ia berdoa meminta hikmat untuk menjaga hidup anaknya. Simson kemudian tumbuh menjadi pahlawan Israel yang kuat dan gagah perkasa pada zamannya dan mengalahkan musuh Israel.

\section{Orangtua Yohanes Pembaptis}

Yohanes pembaptis lahir bagi satu keluarga yang telah lanjut usia, yaitu Imam Zakharia dan Elisabet. Allah mendengar doa Elisabet yang sudah tua dan mandul yang telah kehilangan harapan, Allah menunjukkan kasih setia-Nya dengan mengirimkan seorang putera. Seakan tidak percaya Zakharia berlutut dan memuji Allah-nya atas perbuatan-Nya itu. Nama anak itu Yohanes, sudah menjadi tanda ajaib bagi orang-orang disekitarnya sehingga mulai mempercayai harapan baru datang dari Allah yang telah lama hilang. Pada akhirnya Yohanes Pembaptis menjadi nabi yang membuka jalan bagi kedatangan Juru Selamat.

Melalui orangtua-orangtua dalam kisah di atas kita dapat menyadari betapa pentingnya kesalehan orangtua dalam membina generasi berikutnya. Oleh karena itu marilah kita sebagai orang tua atau orang-orang yang memiliki tanggung jawab untuk mendidik anakanak/generasi ini, dengan terus menunjukkan kesalehan di dalam Tuhan dan dihadapan anakanak generasi ini, sehingga mereka boleh percaya dan hidup berkenan dimata Tuhan. 


\section{DAFTAR PUSTAKA}

Alkitab Penuntun Hidup Berkelimpahan. Jakarta: Lembaga Alkitab Indonesia, 2005.

Homrighousen .E,G. dan I.H.Enklaar. Pendidikan Agama Kristen. Jakarta: BPK Gunung Mulia, 2007.

Reimer.G. Ajarlah Mereka. Pedoman Ilmu Katekese. Jakarta: Yayasan Komunikasi Bina Kasih/OMF, 1999.

Wijanarko, Jarot. Anak di Mata Tuhan. Jakarta: Suara Pemulihan, 2006.

Wilkinson, Bruce H. Teaching With Style. Jakarta: Word Teach Indonesia, 1994.

http://www.danielnugroho.com/faith/hana-ibu-yang-penuh-doa/

http://www.sarapanpagi.org/yohanes-pembaptis-nabi-yahya:vt36.html

Belajar dari Yohanes diambil dari: Belajar dari Yohanes Pembaptis!/e-Artikel 